\title{
Effect of Thermomechanical Cyclic Loading Condition on Two-Way Strain in Ti-Ni-Cu Shape Memory Alloy
}

\author{
Y. Takeda*, T. Yamamoto**, A. Goto** and T. Sakuma** \\ **TAKE R\&D, Shizuoka 426-0087 \\ **Faculty of Engineering, Oita University, Oita 870-1192, tyama@cc.oita-u.ac.jp
}

This study describes the effect of thermomechanical cyclic condition on two-way strain in Ti-Ni-Cu shape memory alloy. The material used in this study is $\mathrm{Ti}-41.7 \mathrm{Ni}-8.5 \mathrm{Cu}(\mathrm{at} \%)$ shape memory alloy. The specimen shape is a wire with $1 \mathrm{~mm}$ diameter and $70 \mathrm{~mm}$ gage length. The specimen was heat treated at $623 \mathrm{~K}$ for $3.6 \mathrm{ks}$. The process of the cyclic loading test in this study is loading-unloading-heating-unloading-cooling cycle. The specimen was loaded to given applied strain and subsequently unloaded. And then, the specimen was heated up to $373 \mathrm{~K}$ or $423 \mathrm{~K}$ and was kept at the temperature for $0.6 \mathrm{ks}$ under the constrained strain condition followed by unloading and cooling under free strain condition. Also, the number of cycles is 30 cycles. This study discussed the effects of heating temperature, applied strain and number of cycles on two-way strain in Ti-41.7Ni-8.5Cu(at \%) shape memory alloy. The two-way strain slightly increases with increasing heating temperature. An increase in the maximum applied strain up to $7.5 \%$ increases the two-way strain. There is hardly effect of the number of cycles on the two-way strain.

Key words: two-way strain, Ti-Ni-Cu shape memory alloy, thermomechanical cycle, applied strain, heating temperature

\section{INTRODUCTION}

In recent years, shape memory alloys (SMAs) are being expected to be put to practical use in the micromechanics field since they have unique characters such as shape memory effect and superelasticity ${ }^{[1]}$. In particular, use of SMAs as an actuator attracts attention, because SMAs allow reduction in size and weight ${ }^{[2,3]}$.

SMA actuators usually employ a one-way shape memory effect. Therefore, SMA actuators require a bias force such as a sprig to return the SMA to its low-temperature shape. However, use of a two-way shape memory effect which memorizes both low-temperature shape and high-temperature shape requires no bias force so that further reduction in size and weight can be expected.

Ti-Ni-Cu alloys are one of promising materials for a component of a SMA actuator, because the recovery stress increases and the stress hysteresis and transformation temperature hysteresis decrease with increasing copper content in the alloys ${ }^{[4,5]}$.

This study carried out thermomechanical cycle tests using Ti-41.7Ni-8.5Cu alloy. Based on the results obtained, this study discussed the effect of applied strain, number of cycles and heating temperature on development of two-way strain.

\section{EXPERIMENTAL PROCEDURES}

The chemical composition of the alloy used in this study is $\mathrm{Ti}-41.7 \mathrm{Ni}-8.5 \mathrm{Cu}(\mathrm{at} \%)$. The specimen shape is a wire with $1 \mathrm{~mm}$ diameter and $70 \mathrm{~mm}$ gage length. The specimen was processed in the following manner; the Ti-Ni-Cu shape memory alloy ingot was made using a high frequency induction vacuum furnace, and then was hot forged and hot extruded followed by cold drawing and intermediate annealing. The cold working ratio
Table I Transformation temperatures and Young's moduli.

\begin{tabular}{|c|c|c|c|c|c|}
\hline \multicolumn{3}{|c|}{$\begin{array}{c}\text { Transformation } \\
\text { temperatures (K) }\end{array}$} & \multicolumn{2}{c|}{$\begin{array}{c}\text { Young's } \\
\text { moduli (GPa) }\end{array}$} \\
\hline $\mathrm{M}_{\mathrm{f}}$ & $\mathrm{M}_{\mathrm{s}}$ & $\mathrm{A}_{\mathrm{s}}$ & $\mathrm{A}_{\mathrm{f}}$ & $\mathrm{E}_{\mathrm{M}}$ & $\mathrm{E}_{\mathrm{A}}$ \\
\hline 331.5 & 332.4 & 332.4 & 346.8 & 12.8 & 63 \\
\hline
\end{tabular}

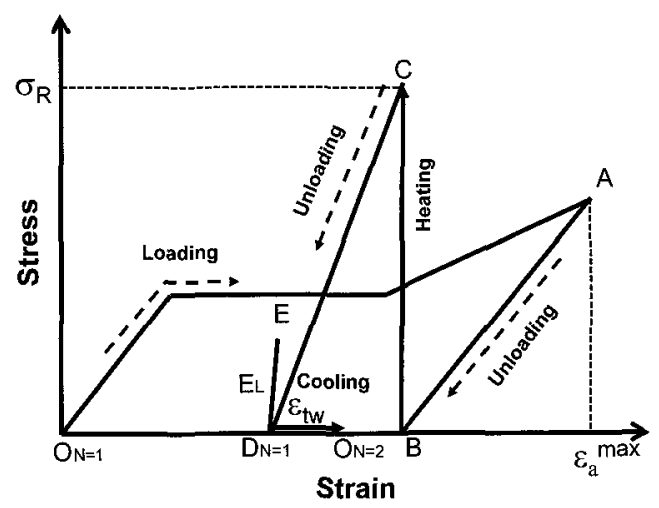

Fig.1 A schematic drawing of thermomechanical cyclic test.

(CW) of the specimen is $10 \%$. Furthermore, the specimen was heat treated at the temperature of $623 \mathrm{~K}$ for $3.6 \mathrm{ks}$ in air.

Martensite start temperature $M_{s}$, martensite finish temperature $\mathrm{M}_{\mathrm{f}}$, austenite start temperature $\mathrm{A}_{\mathrm{s}}$ and austenite finish temperature $A_{f}$ of the specimen measured by differential scanning calorimetry (DSC) are listed in Table I. Young's moduli of martensite phase $E_{M}$ and parent phase $\mathrm{E}_{\mathrm{A}}$ are also listed in Table I. 


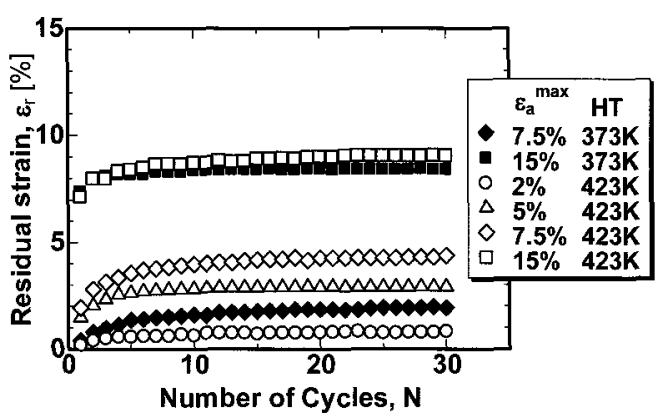

Fig.2 Variation of residual strain with number of cycles.

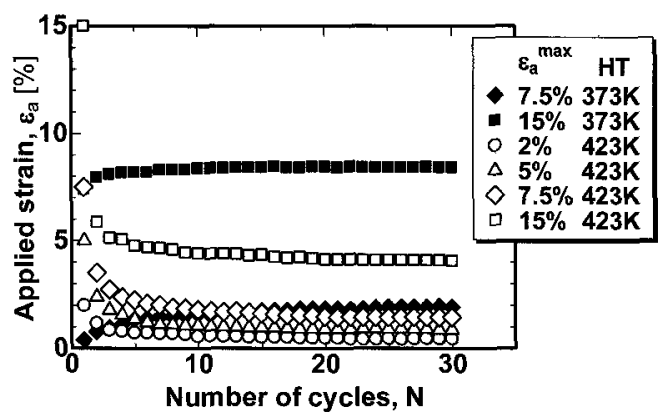

Fig. 3 Variation of applied strain with number of cycles.

To investigate the effect of thermomechanical cyclic loading condition on two-way strain in the Ti-Ni-Cu shape memory alloy, thermomechanical cyclic tests were carried out using the Ti-41.7Ni-8.5Cu (at $\%$ ) alloy wire. Figure 1 shows a schematic drawing of thermomechanical cyclic test. The thermomechanical cyclic test was carried out in the following procedures; (1) The specimen was loaded to given maximum applied strain $\varepsilon_{\mathrm{a}}{ }^{\max }$ ranged from $2 \%$ to $15 \%$ at the isothermal temperature of $263 \mathrm{~K}$ lower than martensite transformation finish temperature $\mathrm{M}_{\mathrm{f}}$, and was subsequently unloaded $\left(\mathrm{O}_{\mathrm{N}=1} \rightarrow \mathrm{A} \rightarrow \mathrm{B}\right)$.

(2) The specimen was heated up to $373 \mathrm{~K}$ or $434 \mathrm{~K}$ at $3 \mathrm{~K} / \mathrm{min}$ and was kept for $0.6 \mathrm{ks}$ under constrained strain condition $(\mathrm{B} \rightarrow \mathrm{C})$. In this process, the recovery stress $\sigma_{\mathrm{R}}$ was obtained as shown in Fig.1. And then, it was unloaded $\left(\mathrm{C} \rightarrow \mathrm{D}_{\mathrm{N}=1}\right)$.

(3) The specimen was loaded to the strain ranged from $0.3 \%$ to $0.4 \%$ which is elastic strain range, and was subsequently unloaded $\left(\mathrm{D}_{\mathrm{N}=1} \rightarrow \mathrm{C} \rightarrow \mathrm{D}_{\mathrm{N}=1}\right)$. The apparent Young's modulus $\mathrm{E}_{\mathrm{L}}$ was evaluated from the incline of stress-strain relation obtained from this process.

(4) The specimen was cooled down to $263 \mathrm{~K}$ at $5 \mathrm{~K} / \mathrm{min}$ under free strain condition. In this process, the two-way strain $\varepsilon_{\mathrm{tw}}\left(\mathrm{D}_{\mathrm{N}=1} \rightarrow \mathrm{O}_{\mathrm{N}=2}\right)$ is caused by the appearance of the two-way shape memory effect.

The process from (1) to (4) mentioned above was defined as one cycle. The point $\mathrm{O}_{\mathrm{N}=\mathrm{i}}$ was set as the start point of $\mathrm{N}=\mathrm{i}$ cycle, and the repeated cycles of the process was 30 cycles. In this study, the residual strain $\varepsilon_{\mathrm{r}}$ was defined as the range from $\mathrm{O}_{\mathrm{N}=1}$ to $\mathrm{D}_{\mathrm{N}=\mathrm{i}}$, the applied strain in each cycle $\varepsilon_{\mathrm{a}}$ the range from $\mathrm{O}_{\mathrm{N}=\mathrm{i}}$ to $\mathrm{A}$, the

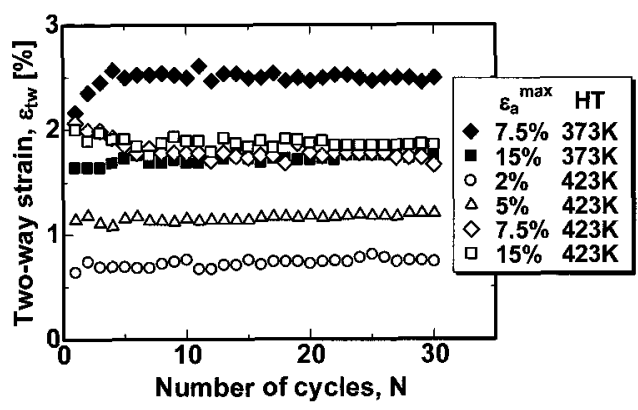

Fig.4 Variation of two-way strain with number of cycles.

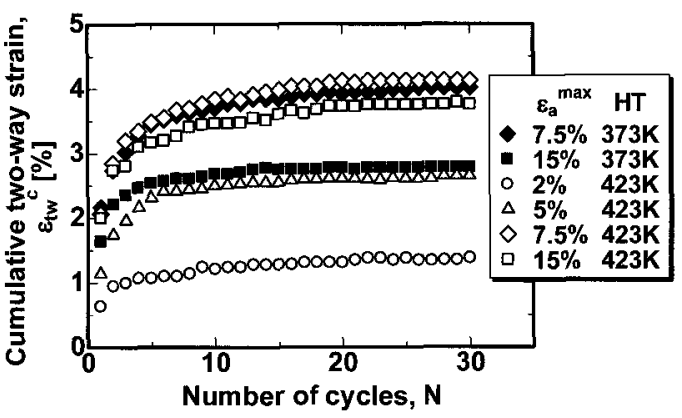

Fig.5 Variation of two-way strain with number of cycles.

two-way strain in each cycle $\varepsilon_{\mathrm{tw}}$ the range from $\mathrm{D}_{\mathrm{N}=\mathrm{i}}$ to $\mathrm{O}_{\mathrm{N}=\mathrm{i}+1}$ and the cumulative two-way strain $\varepsilon_{\mathrm{tw}}{ }^{\mathrm{c}}$ the range from $\mathrm{D}_{\mathrm{N}=1}$ to $\mathrm{O}_{\mathrm{N}=\mathrm{i}+1}$, respectively.

\section{RESULTS AND DISCUSSIONS}

3.1 Effect of thermomechanical cycle loading condition on two-way strain

Figures 2 and 3 show the variation of the residual strain $\varepsilon_{\mathrm{r}}$ with the number of cycles and the variation of the applied strain $\varepsilon_{\mathrm{a}}$ with the number of cycles. The $\varepsilon_{\mathrm{a}}$ decreases with increasing $\varepsilon_{\mathrm{r}}$. On the other hand, an increment of the $\varepsilon_{\mathrm{r}}$ decreases with decreasing $\varepsilon_{\mathrm{a}}$. As a result, the $\varepsilon_{\mathrm{r}}$ increases and the $\varepsilon_{\mathrm{a}}$ rapidly decreases during the first few cycles, and the variation of them with the number of cycles become small after these cycles.

Figures 4 and 5 show the variation of the two-way strain $\varepsilon_{\mathrm{tw}}$ with the number of cycles and the variation of the cumulative two-way strain $\varepsilon_{\mathrm{tw}}{ }^{\mathrm{c}}$ with the number of cycles. In the case of the maximum applied strain $\varepsilon_{\mathrm{a}}{ }^{\max }$ $=7.5 \%$, the $\varepsilon_{\mathrm{tw}}$ slightly decreases in the early cycles. However, there is hardly effect of the number of cycles on the $\varepsilon_{\mathrm{tw}}$. On the other hand, the number of cycles affects the $\varepsilon_{\mathrm{tw}}{ }^{\mathrm{c}}$. The $\varepsilon_{\mathrm{tw}}{ }^{\mathrm{c}}$ increases with the number of cycles up to approximately 15 cycles but become almost constant after these cycles. This is the reason why the $\varepsilon_{\mathrm{tw}}{ }^{\mathrm{c}}$ includes the inclement of the residual strain $\varepsilon_{\mathrm{r}}$.

Figure 6 shows the relationship between the two-way strain and the maximum applied strain $\varepsilon_{\mathrm{a}}{ }^{\max }$. The reason for the appearance of two-way strain may be considered due to the internal stress occurring at the interface 


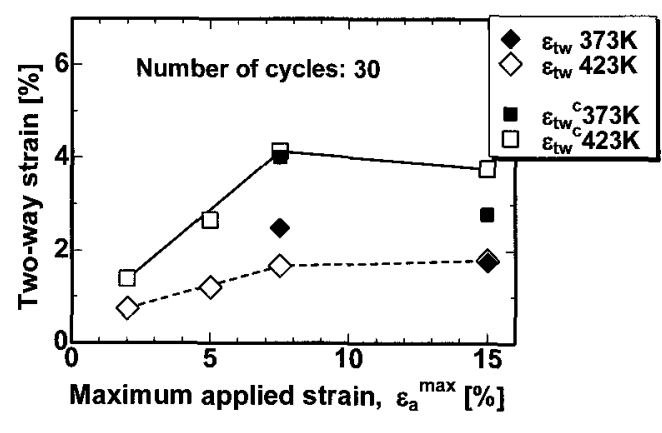

Fig.6 Relation ship between two-way strain and maximum applied strain.

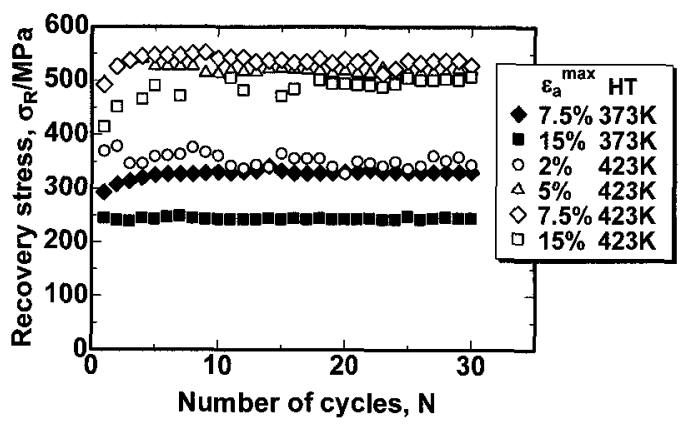

Fig.7 Variation of recovery stress with number of cycles.

between the recoverable martensite phase and the damaged irrecoverable martensite phase ${ }^{[6]}$. The two-way strain $\varepsilon_{\mathrm{tw}}$ and cumulative two-way strain $\varepsilon_{\mathrm{tw}}{ }^{\mathrm{c}}$ increase with increasing $\varepsilon_{\mathrm{a}}{ }^{\max }$ up to $7.5 \%$. However, the further increase in the $\varepsilon_{\mathrm{a}}{ }^{\max }$ tends to decrease the $\varepsilon_{\mathrm{tw}}$ and $\varepsilon_{\mathrm{tw}}{ }^{\mathrm{c}}$. The reason is considered as follows. An increase in the $\varepsilon_{\mathrm{a}}{ }^{\max }$ up to $7.5 \%$ increases both the recovery strain and the residual strain so that the internal stress increases. And then the further increase in $\varepsilon_{a}{ }^{\max }$ decreases the recovery strain because of the increase of residual strain caused by slip, thus, the internal stress decreases. Additionally, the $\varepsilon_{\mathrm{tw}}$ slightly increases with increasing heating temperature at the $\varepsilon_{a}{ }^{\max }=7.5 \%$.

The variation of the recovery stress $\sigma_{R}$ with the number of cycles is shown in Fig.7. Slight increase of the $\sigma_{\mathrm{R}}$ in the early cycles is found in some cases but there is hardy effect of the number of cycles on the $\sigma_{\mathrm{R}}$. Also, an increase in the $\varepsilon_{a}{ }^{\max }$ up to $7.5 \%$ increases the $\sigma_{R}$ but the further increase in the $\varepsilon_{\mathrm{a}}{ }^{\max }$ decreases the $\sigma_{\mathrm{R}}$. This indicates that an increase in the $\varepsilon_{a}{ }^{\max }$ more than $7.5 \%$ decreases the recoverable martensite phase because of the increase of the damaged irrecoverable martensite phase caused by slip.

\subsection{Evaluation of two-way strain by volume fraction of slip-deformed martensite}

The slip-deformed martensite phase does not transfer to the parent phase by heating, and remains locally in the parent phase ${ }^{[7]}$. Authors have defined the remained fraction of martensite phase in the parent phase as the volume fraction of slip-deformed martensite $\xi$, and have

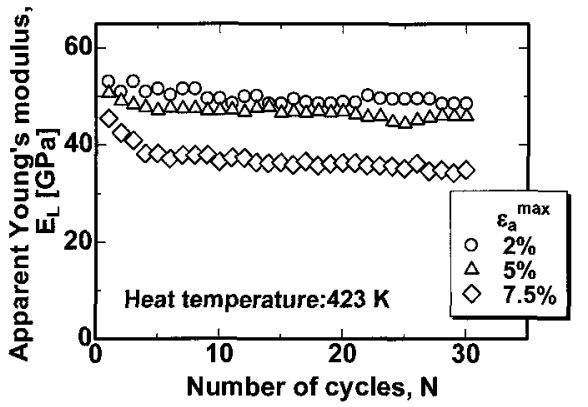

Fig. 8 Variation of apparent Young's modulus with number of cycles.

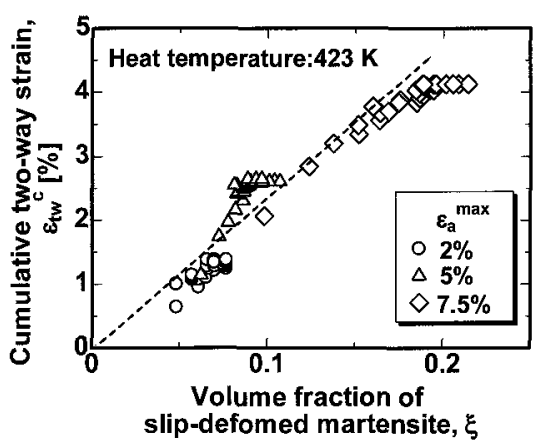

Fig.9 Relationship between cumulative two-way strain and volume fraction of slip-deformed martensite.

clarified that the volume of $\xi$ can be used as a criterion of applied strain induced dislocation ${ }^{[8-10]}$.

In the thermomechanical cyclic test of this study, the internal damage in material occurs in the process of (1) and (2). In the process of (1), the internal damage in material is induced by the applied strain. In the process of (2), the recovery stress is generated by the reverse transformation with an increase in temperature. Since there are both the parent phase and martensite phase in the material during the process of the reverse transformation, the slip deformation occurs in the martensite phase having the lower critical stress for slip by the recovery stress ${ }^{[7]}$. In addition, the variation of the fraction of slip-deformed martensite emerges as the variation of the apparent Young's modulus $E_{L}$.

The variation of the apparent Young's modulus $\mathrm{E}_{\mathrm{L}}$ with the number of cycles is shown in Fig.8. The $E_{L}$ decreases with increasing the number of cycles in the early cycles and then become almost constant after these cycles. This result is believed that the slip-deformed martensite phase increases with increasing number of cycles in the early cycles and then hardly increases after these cycles. Also, an increase in the $\varepsilon_{\mathrm{a}}{ }^{\text {max }}$ decreases the $\mathrm{E}_{\mathrm{L}}$. This indicates that an increase in the $\varepsilon_{\mathrm{a}}{ }^{\max }$ increases the slip-deformed martensite phase.

The volume fraction of slip-deformation martensite $\xi$ is defined as the following equation ${ }^{[8,9]}$, where, $E_{A}$ and $\mathrm{E}_{\mathrm{M}}$ are Young's moduli of parent phase and martensite phase, respectively. 


$$
\xi=\frac{E_{M}\left(E_{A}-E_{L}\right)}{E_{L}\left(E_{A}-E_{M}\right)}
$$

Figure 9 shows the relationship between the cumulative two-way strain $\varepsilon_{\mathrm{tw}}^{\mathrm{c}}$ and volume fraction of slip-deformed martensite $\xi$. The $\varepsilon_{\mathrm{tw}}{ }^{\mathrm{c}}$ lineally increases with increasing $\xi$. This result shows that the $\xi$ can be used as a criterion of $\varepsilon_{\mathrm{tw}}{ }^{\mathrm{c}}$.

\section{CONCLUSIONS}

Thermomechanical cyclic tests were carried out using the $\mathrm{Ti}-41.7 \mathrm{Ni}-8.5 \mathrm{Cu}(\mathrm{at} \%)$ alloy in order to studying effect of thermomechanical cycle loading condition on two-way strain in Ti-Ni-Cu shape memory alloy. The obtained results are summarized as follows;

(1) An increase in the maximum applied strain up to $7.5 \%$ has increased the two-way strain.

(2) There has been hardly effect of the number of cycles on the two-way strain.

(3) The two-way strain slightly has increased with increasing heating temperature at the maximum applied strain of $7.5 \%$.

(4) The volume fraction of slip-deformation martensite can be used as a criterion of cumulative two-way strain.

\section{ACKNOWLEDGEMENT}

Part of this study was supported by Grant-in-Aid for Scientific Research (C) (19560095).

\section{REFERENCES}

[1] T. Honma, J. Jpn. Soc. Mech. Eng., 87, 517-522 (1984).

[2] D. Homma, Journal of the Robotics Society of Japan, 8-4, 107-109 (1990).

[3] D. Homma, J. Jpn. Inst. Met., 77-84 (1989).

[4] S. Miyazaki, K. Mizukoshi, T. Ueki, T. Sakuma and Y. Liu, Mater. Sci. and Eng., A273-275, 658-63 (1999).

[5] T. Sakuma, U. Iwata, H.Takaku, N. Kriya, Y. Ochi, and T. Matsumura, Trans. Japan Soc. Mech. Eng., A66-664 748-54 (2000).

[6] K. Okita, N. Okabe, T. Sato and T. Nakao, Mater. Trans., 47-3, 753-758 (2006).

[7] S. Miyazaki, T. Imai, Y. Igo and K. Otsuka, Metallurgical Transaction A, 17A, 115 (1986).

[8] T. Sakuma, M. Hosogi, N. Okabe, U. Iwata and K. Okita, Mater. Trans., 43, 815-821(2002).

[9] T. Sakuma, M. Hosogi, N. Okabe, U. Iwata and K. Okita, Mater. Trans., 43, 828-833(2002).

[10] T. Sakuma, Y. Mihara, Y. Ochi and K. Yamauchi, J. Japan Inst. Metals., 69-8, 568-574 (2005). 